\title{
SPATIAL MARKET EXPANSION THROUGH MERGERS
}

\author{
Verónica Durán-Carbó \\ Universitat Pompeu Fabra \\ Charles ReVelle \\ The Johns Hopkins University \\ Daniel Serra ${ }^{1}$ \\ Universitat Pompeu Fabra
}

In this paper we present a model that studies firm mergers in a spatial setting. A new model is formulated that addresses the issue of finding the number of branches that have to be eliminated by a firm after merging with another one, in order to maximize profits. The model is then applied to an example of bank mergers in the city of Barcelona. Finally, a variant of the formulation that introduces competition is presented together with some conclusions.

Keywords: mergers, facility location, spatial competition

JEL: C61-J80

\footnotetext{
${ }^{1}$ This research has been supported partially by grant SEC2003-1991 from the Ministry of Research and Science, Spain.
} 


\section{Introduction}

A major reason why companies decide to expand geographically via a merger relates to the exploitation of potential cost and revenue synergies from merging. Indeed, in recent years, a merger wave among firms has occurred, including some mega mergers among large firms, driven by the desire to achieve greater cost and revenue synergies. Several economic sectors are especially sensitive to mergers.

The banking sector, among others, has been experiencing worldwide in the past decades big mergers among banks. A reason frequently given for bank mergers is the potential cost synergies that may exist. For example, in 1996, Chase Manhattan and Chemical Bank merged, creating the (then) largest banking organization in the United States with assets of $\$ 300$ billion. Annual cost savings fom the merger were estimated at $\$ 1.5$ billion, to be achieved by consolidating certain operations and eliminating redundant costs, including the elimination of some 12,000 positions from a combined staff of 75,000 located in 39 states and 51 countries. The $\$ 30$ billion merger of BancOne and First Chicago in 1998 was estimated to produce \$930 million in cost savings and \$275 million in additional revenue resulting from synergies in their credit card and retail and commercial banking business. Similarly, Milwaukee-based Firstar's \$18.7 billion acquisition of Minneapolis-based U.S. Bancorp in late 2000 was expected to reduce combined expenses by $\$ 206$ million per year (an amount equivalent to 5 percent of the combined bank's expenses prior to the acquisition) and Boston-based FleetFinancial's purchase of New Jersey’s Summit Bancorp for $\$ 7$ billion in 2001 was estimated to save as much as $\$ 275$ million in annual expenses (or about 30 percent of the combined banks expenses). In both cases, cost savings were estimated to come through the closing of overlapping branches and laying off personnel. Finally, in 2001 First Union acquired Wachovia for $\$ 14.6$ billion. The merger of these two North Carolina banks was 
expected to reduce annual expenses by $\$ 890$ million through the consolidation of 250 to 300 branches and cutting of some 7,000 jobs. In Europe, after the merger of Bank Austria and Creditanstalt AG in Austria, 70 of the 470 bank branches of the combined firm were closed in 2002.

Several studies have analyzed the economic and financial consequences of bank mergers. Rhoades (1998) looked at nine large bank mergers with substantial market overlap in the early 1990s. He found that all produced significant cost cutting in line with the pre-merger projections due to branch reductions. Piloff (1996) looked at 48 bank mergers in the 1980s, relating announcement period abnormal returns to accounting based performance measures. He found higher abnormal returns that offer the greatest potential for cost reductions (measured by geographic overlap and premerger cost measures). Piloff also found that industry-adjusted profitability of the merged banks does not change, that total expenses to assets increases, and that revenues rise in the five year period around the merger. Houston, et al. (2001) looked at analysts' estimates of projected cost savings and revenue enhancements associated with bank mergers. They found that analysts' estimates of increases in combined bank value associated with a merger are due mainly to estimated costs savings rather than projected revenue enhancements. Finally, Avery, et al. (1999) looked at mergers during the period 1975 through 1998 involving banks with significant geographic overlap (measured by the number of branches in a ZIP code per capita). They found that these mergers resulted in a significant decrease in branches per capita.

In this paper we present a model that addresses the issue of mergers in a spatial setting. In the next section a new model is formulated that addresses the issue of finding the number of branches that have to be eliminated by a firm after merging with another one, in order to maximize revenues. The model then is applied to an example in the city of 
Barcelona. Finally, a variant of the formulation is presented together with some conclusions.

\section{The Merger Delocation Model}

Suppose a region where several firms are spatially competing for customers. Let us consider that this region is represented by discrete points (nodes) in a connected network. Each node has a parameter that can represent population or local demand for the product/service offered in the region. Several firms are operating in that market with competition "a la Hotelling", that is, the demand is captured by the closest outlet, regardless of ownership. The product sold is homogeneous across firms.

There are two players, conceptually, each one of them with a set of stores distributed across the landscape. The players are firm A and firm B, where A is considering merging with B. The stores of each firm are considered all of the same type. Their market regions overlap in some areas and not in other areas.

Firm A is trying to become a more dominant player and has enough resources to merge with B, which would then convert to A type stores with A's branded merchandise or maybe under a new brand name, but offering the same products and services as before. The bargain between A and B to merge will depend not only on what A and B can afford but also on the revenue and return potential that will accrue to $\mathrm{A}$ and $\mathrm{B}$ from merging into a single firm. The two players do have some overlap so that some stores of A or B type will likely be closed if A merges with B. The analysis we are proposing would determine the maximum amount that A should pay for B's stores.

Let's define the following parameters and variables:

$J_{A}=$ set of store sites for A

$J_{B}=$ set of store sites for B

$J=J_{A} \mathrm{U} J_{B}$

$i, I=$ Index and set of demand areas that A and B currently serve 
$a_{i}=$ demand at $i$, the demand that would be served if the store were at $i$

$d_{i j}=$ distance between demand area $i$ and store $j$

$u_{i j}=$ the demand at $i$ that will seek service at $j$ if there is no intervening store

$v_{i}=$ net revenue derived from a unit of demand (demand may have units of trips/year

and $v_{i}$ may have units of $€$ /trip). Net revenue is income less the cost of goods

$N_{i}=\{j$, such that any flow from $i$ to $j$ will still be positive $\}$

$f_{j}=$ Cost to operate store $j$ per year. This includes staffing, utilities, taxes, debt services, leasing, if store is leased, and if it is a B type store the annualized cost of converting the store to an A type.

$x_{i j}=1$, if demand at $i$ is assigned to a store at $j ; 0$, otherwise

$y_{j}=1$, if store $j$ is retained open; 0 , otherwise

The demand function $u_{i j}$ deserves some comments. For A's old customers the function is likely to decline rapidly when the distance between area $i$ and store $j$ increases. We will consider $u_{i j}$ as a lineal function (see Figure 1). If we suppose that a store is at area $i$, then the distance $d_{i j}$ will be 0 and A customers do not need to travel further to A's closest competitor. A similar pattern might be observed for B's former customers.

Figure 1: The demand in node $i$ as a function of distance

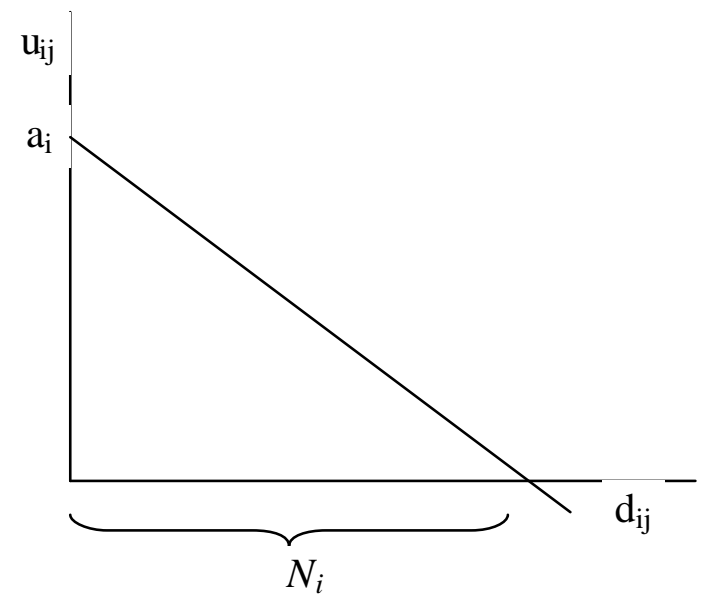

The set $N_{i}$ contains all the stores that are located close to demand node $i$ and that have a positive flow, that is, $u_{i j}>0$.

The formulation of the model is the following: 


$$
\begin{aligned}
& \max Z=\sum_{i \in I} \sum_{j \in N_{i}} v_{i} u_{i j} x_{i j}-\sum_{j \in J} f_{j} y_{j} \\
& \text { s.t. } \\
& \sum_{j \in N_{i}} x_{i j}=1 \quad \forall i \in I \\
& y_{j} \geq x_{i j} \quad \forall i \in I, \forall j \in N_{i} \\
& y_{j}, x_{i j}=\{0,1\} \quad \forall i \in I, \forall j \in N_{i}
\end{aligned}
$$

The first set of constraints (equation 2) forces each demand node to be assigned to only one store with positive flow. The third set of constraints allows a facility to be assigned to a demand node only if it remains open, that is, when the model is solved, $y_{j}=1$ means that a store previously open remains open. If $y_{j}=0$, a store previously open now closes and all its associated costs exit the profit equation. The closest store could be an A type store or a B type store. Observe that the set of constraints is very similar to one corresponding to the p-median model. The only difference is that in the $p$ median constraint set includes a constraint that fixes the number of facilities to be located. In the merger model, the analysis is not only determining profit associated with the acquisition but also which stores are likely to be closed. The problem is not very large because the stores do not reach very far, in the sense that customers are not willing to or are not required to travel far because competition from players C. The problem resembles, but is far smaller than, the Maximum Profit Plant Location Problem (Jucker and Carlson 1976, ReVelle and Laporte 1997). The number that comes from this analysis is the profit from the combined system of stores.

If we assume that instead of a merger, Firm A is seeking to purchase all Firm B outlets, the profit from the system of A's stores is subtracted from the number giving the profit on the purchase. This last number, call it $\mathrm{P}$, when divided by the acquisition cost $\mathrm{D}$ may be required to be at least alpha: 


$$
\frac{P}{D} \geq \alpha \quad \text { or } \quad D \leq \frac{P}{\alpha}
$$

giving us an upper bound on the amount that A might offer for B stores.

$N_{i}$ contains the set of stores $j$ that make function $u_{i j}$ positive. The maximum distance $\left(d_{\max }\right)$ that make function $u_{i j}=0$ is a parameter of the problem. If we choose a store $j$, which is not at $N_{i}$, function $u_{i j}$ will take negative values. This mean that the cost to operate store $j$ at area $i$ is bigger than the net revenue that will apport.

As we will see in the next section of the paper, the number of stores of firm A or B that remain open which maximizes function $\mathrm{Z}$ depends on $d_{\max }$. The larger the value of $d_{\max }$ the smaller is the number of stores that will remain open after solving the merger problem.

\section{A Theoretical Application}

The integer linear model presented was solved using LINGO. To get some results and prove its utility we have considered the cost to operate store $j$ per year the same for all stores.

The Swain's 55-node region has been used (see Appendix A.1), and we have considered the same number of areas $(i)$ and stores $(j)$. In other words, we have supposed that every area has a store $(\# I=\# J=55)$. Therefore, we are going to optimize the number of stores that maximize Z. It is necessary to remember that the model we are studying, to maximize Z, close stores and leave in the same place stores which remain open, but does not move stores from an area to another, because it uses the stores of the firms A and B that were open before the merger. In other words, no re-location is allowed.

For each node, the associated demand function is lineal and decreases when distance increases. The parameter $u_{i j}$ is a function of $d_{i j}$, i.e., $u_{i j}=u_{i j}\left(d_{i j}\right)$. When the distance is 
equal to zero the utility function is equal to $a_{i}$, and when the distance $d_{i j}$ is equal to $d_{\max }$ $\left(d_{i j}=d_{\max }\right)$ then $u_{i j}$ is zero. The demand function is defined as follows:

$$
\begin{aligned}
& u(d)=\alpha+\beta d \\
& \left.\begin{array}{l}
u(d)=\alpha+\beta d \\
u(0)=a
\end{array}\right\} \Rightarrow a=\alpha+\beta 0 \\
& \left.\begin{array}{l}
u(d)=a+\beta d \\
u\left(d_{\max }\right)=0
\end{array}\right\} \Rightarrow 0=a+\beta d_{\max } \Rightarrow \beta=\frac{-a}{d_{\max }} \\
& u(d)=a+\left(-\frac{a}{d_{\max }}\right) d
\end{aligned}
$$

Therefore, the demand function will be: $u(d)=a\left(1-\frac{1}{d_{\max }} d\right)$

To compare the results we will obtain in function of $d_{\max }$, we have considered three different values for $d_{\text {max }}$, the next table contains the value of the objective function and the number of stores that stay open in order to maximize the profits in the region we are interested in.

\begin{tabular}{|c|c|c|}
\hline Maximum distance & Objective function & Number of outlets \\
\hline 200 & $265.551,60$ & 22 \\
\hline 300 & $288.585,20$ & 11 \\
\hline 400 & $306.815,50$ & 8 \\
\hline
\end{tabular}

As we can see in the table when distance increases, the objective function increases and the number of stores which remain open, decreases.

In this example, the value of the fixed $\operatorname{cost} f_{j}$ is set arbitrarily, since the relevant issue is that the value of the objective function increases as the maximum distance increases. This happens because the set $N_{i}$ gets larger as the distance increases, and there are more summands in the first part of $\mathrm{Z}$ that make it increase.

The number of stores decreases when distance increases. This happens because the set $N_{i}$, that makes the utility function positive, increases with the maximum distance. 
Remember that the maximum distance makes utility function zero, and stores that are in the set $N_{i}$ have a positive utility function for the area $i$.

\section{A Real Application}

In this section, we will consider the city of Barcelona, divided in 321 areas. We will study the merger between two existing savings banks, Caixa de Girona and Caixa de Manlleu.

We have chosen these two banks because they both have a similar number of branch offices in the metropolitan area of Barcelona. Caixa de Girona is larger than the other savings bank; therefore we will assume that the first one wants to acquire the second one.

The offices of these two banks are in general, as many banks in big cities, concentrated in the CBD as shown in Figure 1. Before solving optimally the model, our logic says that it is probable that after the merger some offices located in the center will close and the ones in the city boundaries will remain open.

The distance between the centroïds of the areas is measured in minutes. In the previous section the distance matrix was measured in meters, and we used the maximum distance, $d_{\max }$, as the value that made the utility function $u_{i j}=0$. Now that the same matrix is measured in minutes, we have to use the maximum time, $t_{\max }$. This is the maximum time we consider a person is willing to walk to go from the area s/he lives to a bank office. We have 321 areas, \#I = 321, and since each saving bank considered has ten offices in Barcelona, then $\# \mathbf{J}=20$. We have chosen random values for the cost to operate store $j$ per year, $f_{j}$, , so the value of the objective function is not representative in monetary terms. 
Figure 2: Map of the location of branch offices in the city of Barcelona

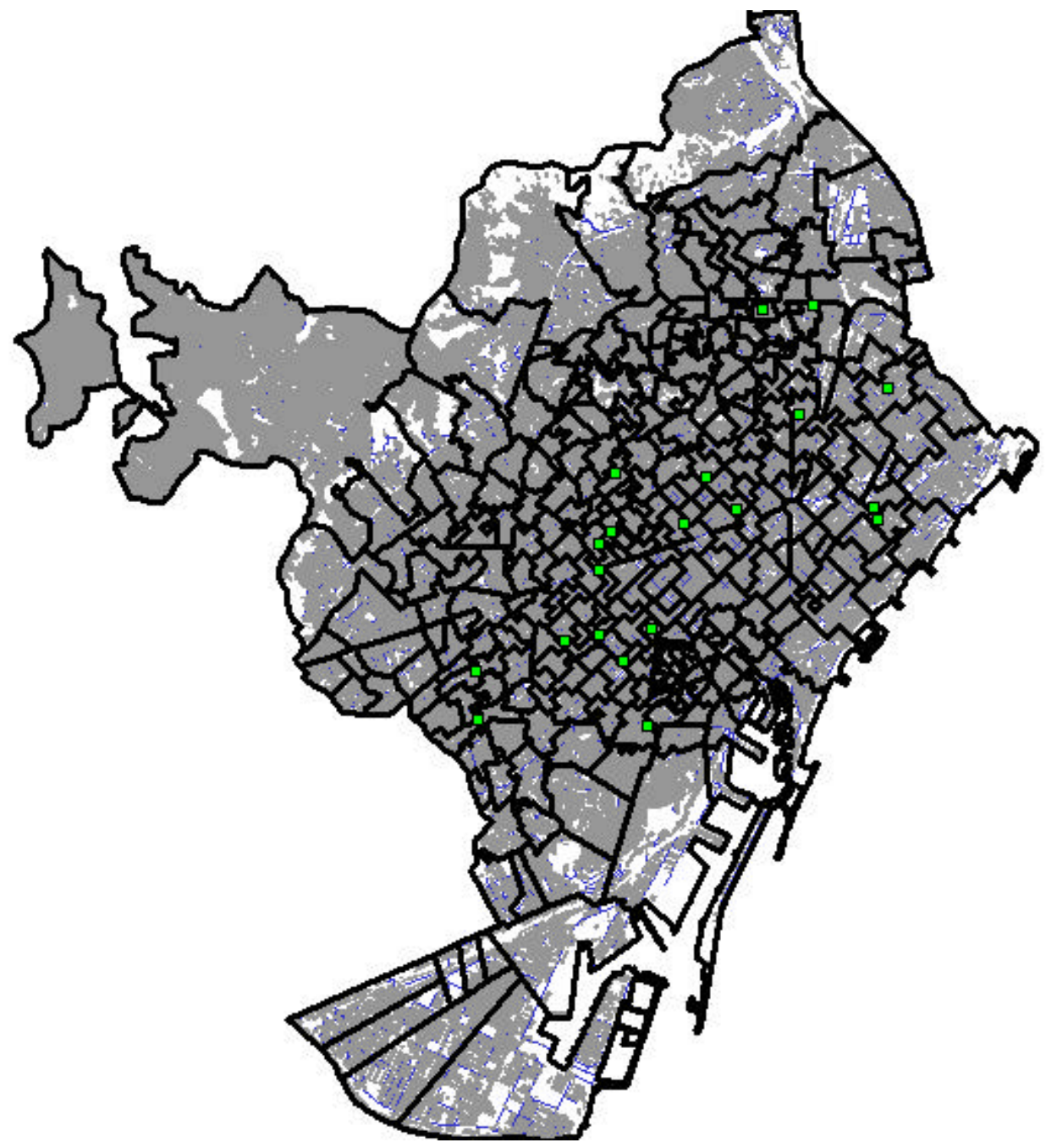

As we did in the past section, we have chosen three different values for $t_{\max }$ to compare the results of the model.

Next table shows the results:

\begin{tabular}{|c|c|c|}
\hline Maximum time & Objective function & Number of outlets \\
\hline 10 & $42.481,68$ & 7 \\
\hline 20 & $90.686,50$ & 6 \\
\hline 30 & $108.725,20$ & 4 \\
\hline
\end{tabular}

As occurred in section 3, objective function increases with the distance, and the number of stores that remain open decreases.

Figure 3 shows the position of stores remaining opened with different maximum times. 
Figure 3: Map of the location of branch offices in the city of Barcelona after the merger
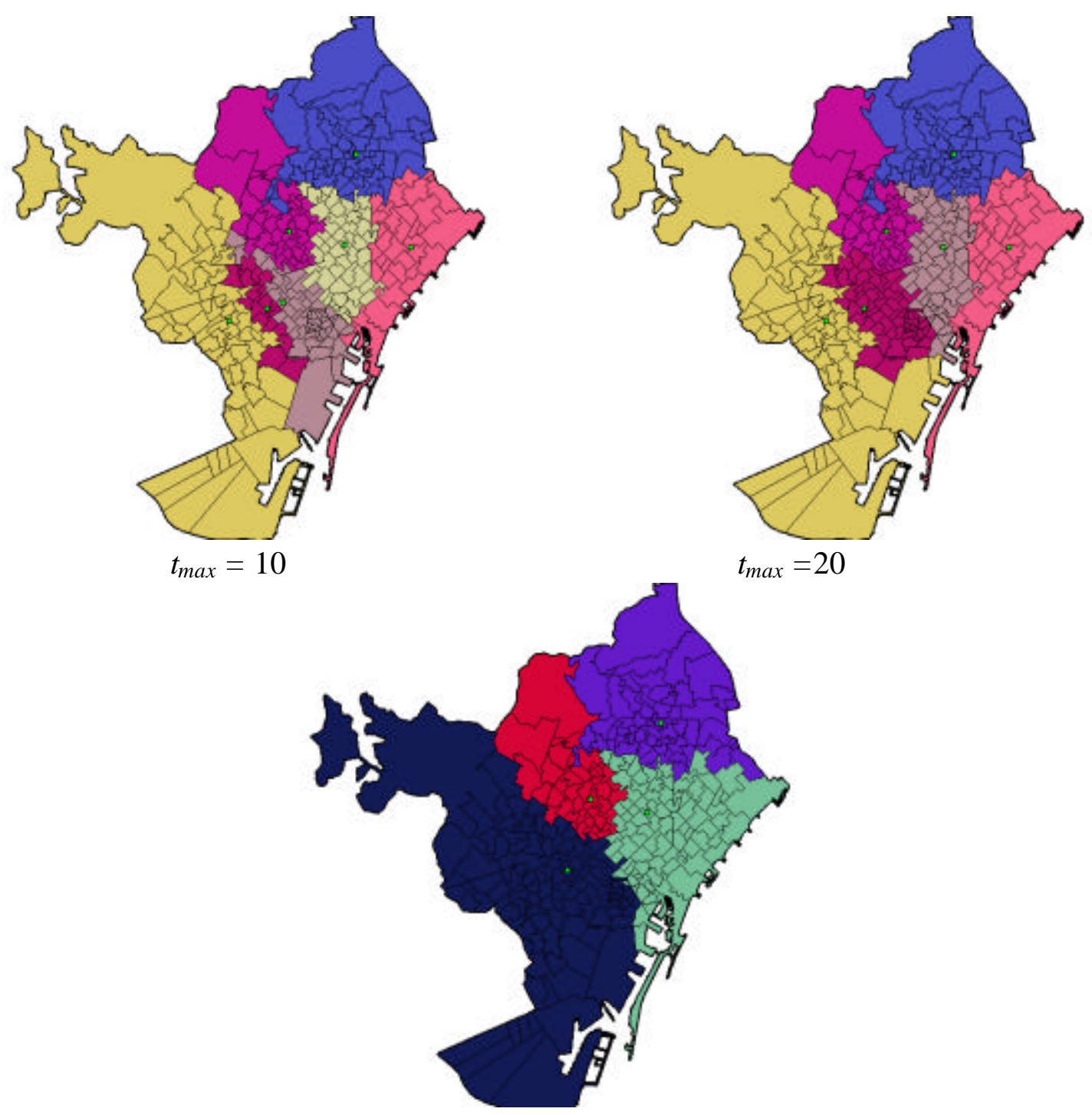

$$
t_{\max }=30
$$

We can see in the different cases, as we have supposed, that many branch offices, which where in the center, have been closed, while the ones sited around the city remain open If we compare the distribution of areas between $t_{\max }=10$ and $t_{\max }=20$, we can see that they are very similar. The reason is that in the first case only one more office is opened than in the second case. The areas that were assigned to the office that was closed in the second case, have almost all been assigned to the same office when $t_{\max }=20$. 


\section{Model extensions}

So far, in the model presented we have assumed that there are no competitors other than both Firms A and B. Suppose now that there are three players, each one of them with a set of stores distributed across the land scape. The players are firm A, firm B and firm $\mathrm{C}$, where $\mathrm{A}$ is considering to merge with $\mathrm{B}$. Firm $\mathrm{C}$ is thought of all other firms operating in that market with their stores. The stores of all firms are considered all of the same type. Their market areas overlap in some areas and not in other areas.

The issue of competition from $\mathrm{C}$ suggests the possibility of a second model that uses the notion of "capture" (ReVelle, 1986, Serra and ReVelle 1994). For simplicity, we set an initial threshold for the problem of $S_{i}$, the distance from $i$ to the nearest type C store, the blend of competitors who remain on the landscape after the acquisition of B and A. The utilization of one of the outlets of A or B by customers at $i$ would be expected to fall rather steeply. If the $\mathrm{A}$ or $\mathrm{B}$ outlet that remains on the landscape is further from $i$ than $S_{i}$, the distance or time to the nearest competitor C, then costumers of firms A or B will choose outlets from firm $\mathrm{C}$. That is, the assumption on consumer choice is a sensitivity to time or distance rather than any distinction of product or service. If competitors' outlets are considered (Firm C), the demand function for the merging firms is given by Figure 4.

We again use the $i$ and $j$ notation for this capture model, but replace $u_{i j}$ with $a_{i}$ so long as $d_{i j}<S_{i}$ (ignoring ties). We still use $y_{j}$ as the $0-1$ siting variable but $Q_{i}$ replaces $N_{i}$, where $Q_{i}=\left\{j / d_{i j}<S_{i}\right\}$. We define $w_{i}=1$ if the demand at $i$ is captured, and 0 otherwise. That is, $Q_{i}$ consists on those $j$ in $\mathrm{J}_{\mathrm{A}} \mathrm{U} \mathrm{J}_{\mathrm{B}}$ that are closer to $i$ than $S_{i}$. Demand at $i$ is fully captured if one of these $j$ has an outlet. The problem is to 


$$
\begin{array}{ll}
\max Z=\sum_{i \in I} a_{i} v_{i} w_{i}-\sum_{j \in J} f_{j} y_{j} \\
\text { s.t. } \\
w_{i} \leq \sum_{j \in Q_{i}} y_{j} \quad \forall i \in I \\
w_{i} \in\{0,1\}
\end{array}
$$

As we can see, both models are very similar. The second model has a simpler formulation. When we use the first model, we only take into account the firms that are doing the merger, but not in other firms. However, when we use the second model, we study the position of competitor firms to remove outlets. A similar model has been studied by Murray, ReVelle and Serra (2005) for the public sector.

\section{Figure 4: The demand in $i$ as a function of distance (C competitor nearby)}

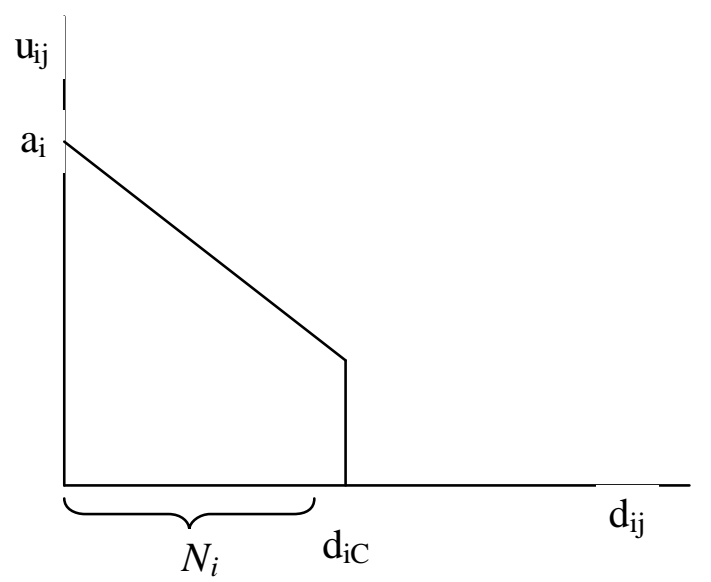

\section{Conclusions}

In this paper, a new location model has been presented. This model chooses outlets to be removed in order to maximize total revenue in the merger. The model finds the number of outlets and their locations that have to be closed to maximize $\mathrm{Z}$. In the real example, we have studied the location of branch offices from two different bancs sited in Barcelona. The number total of offices before the merger was 20. We have seen that 
the number of outlets before the merger depends on a parameter that is related with the maximum time needed to go from an area to an outlet. We have seen that as the maximum time increases, the number of stores that remains open decreases.

We have studied the merger between firms, something every day more common in market. In our model, we are using outlets that were opened before the merger to make a new distribution. This implies that areas that were far from outlets of both firms before the merger, still remain far after it, since no new locations are found.

We have supposed from the beginning the assumption on consumer choice is based on time or distance rather than any distinction of product or service. These models can be modified by introducing consumer-choice attributes other than distances or travel times, such as quality of service, as studied by Serra et al. (1999) and Colomé and Serra (2001), or the introduction of price decisions together with location decisions (see, for example, Serra and ReVelle 1999). 


\section{References}

Avery, R.B., R.W. Bostic, P.S. Calem, and G.B. Canner (1999): "Consolidation and bank branching patterns". Journal of Banking and Finance 23, 497-532.

Colomé R. y D. Serra (2001): "Consumer Choice and Competitive Location Models: Formulations and heuristics" Papers in Regional Science, 80(4), 425-438

Houston, J.F., C.M. James, and M.D. Ryngaert (2001): "Where do merger gains come from? Bank mergers from the perspective of insiders and outsiders". Journal of Financial Economics 60, 285-331.

Jucker, J.V. and R.C. Carlson (1976): "The Simple Plant-Location Problem under Uncertainty," Operations Research, 24(6), 1045-1055.

Piloff, S.J. (1996): "Performance changes and shareholder wealth creation associated with mergers of publicly traded banking institutions". Journal of Money, Credit, and Banking 28, 294-310.

ReVelle, C. (1986): "The Maximum Capture or "Sphere of Influence" Location problem: Hotelling revisited on a Network". Journal of Regional Science 26(2), 343358.

ReVelle, C, and G. Laporte (1997): "The plant location problem: new models and research prospects", Location Science 5(3), 203-223

ReVelle, C., Murray, A. and D. Serra (2005): "Location models for ceding market share and shrinking services", OMEGA, The international Journal of Management Science, forthcoming

Rhoades, S.A. (1998): "The efficiency effects of bank mergers: An overview of case studies of nine mergers". Journal of Banking and Finance 22, 273-291.

Serra D., Eiselt H., Laporte G. and C. ReVelle (1999): "Market Capture Models under Various Customer Choice Rules". Environment and Planning B, 26(5), 141-150

Serra D. and C. ReVelle (1999): "Competitive Location and Pricing on Networks" Geographical Analysis, 31(2), 109-129.

Serra D. and C. ReVelle (1994): "Market Capture by two Competitors: The Pre-emptive Capture Problem", Journal of Regional Science 34(4), 549-56 
Appendix A.1: 55-node network data

\begin{tabular}{|l|l|l|l|l|l|l|l|}
\hline NODE & POPN & COORD X & COORD Y & NODE & POPN & COORD X & COORD Y \\
\hline 1 & 710 & 32 & 31 & 29 & 60 & 19 & 38 \\
\hline 2 & 620 & 29 & 32 & 30 & 60 & 27 & 41 \\
\hline 3 & 560 & 27 & 36 & 31 & 60 & 21 & 35 \\
\hline 4 & 390 & 29 & 29 & 32 & 50 & 32 & 45 \\
\hline 5 & 350 & 32 & 29 & 33 & 50 & 27 & 45 \\
\hline 6 & 210 & 26 & 25 & 34 & 50 & 32 & 38 \\
\hline 7 & 200 & 24 & 33 & 35 & 50 & 8 & 22 \\
\hline 8 & 190 & 30 & 35 & 36 & 50 & 15 & 25 \\
\hline 9 & 170 & 29 & 27 & 37 & 50 & 35 & 16 \\
\hline 10 & 170 & 29 & 21 & 38 & 40 & 36 & 47 \\
\hline 11 & 160 & 33 & 28 & 39 & 40 & 46 & 51 \\
\hline 12 & 150 & 17 & 53 & 40 & 40 & 50 & 40 \\
\hline 13 & 140 & 34 & 30 & 41 & 40 & 23 & 22 \\
\hline 14 & 120 & 25 & 60 & 42 & 40 & 27 & 30 \\
\hline 15 & 120 & 21 & 28 & 43 & 40 & 38 & 39 \\
\hline 16 & 110 & 30 & 51 & 44 & 40 & 36 & 32 \\
\hline 17 & 100 & 19 & 47 & 45 & 30 & 32 & 41 \\
\hline 18 & 100 & 17 & 33 & 46 & 30 & 42 & 36 \\
\hline 19 & 90 & 22 & 40 & 47 & 30 & 36 & 26 \\
\hline 20 & 90 & 25 & 14 & 48 & 30 & 15 & 19 \\
\hline 21 & 90 & 29 & 12 & 49 & 30 & 19 & 14 \\
\hline 22 & 80 & 24 & 48 & 50 & 30 & 45 & 19 \\
\hline 23 & 80 & 17 & 42 & 51 & 30 & 27 & 5 \\
\hline 24 & 80 & 6 & 26 & 52 & 20 & 52 & 24 \\
\hline 25 & 80 & 19 & 21 & 53 & 20 & 40 & 22 \\
\hline 26 & 70 & 10 & 32 & 54 & 20 & 40 & 52 \\
\hline 27 & 60 & 34 & 56 & 55 & 20 & 42 & 42 \\
\hline 28 & 60 & 12 & 47 & & & & \\
\hline
\end{tabular}

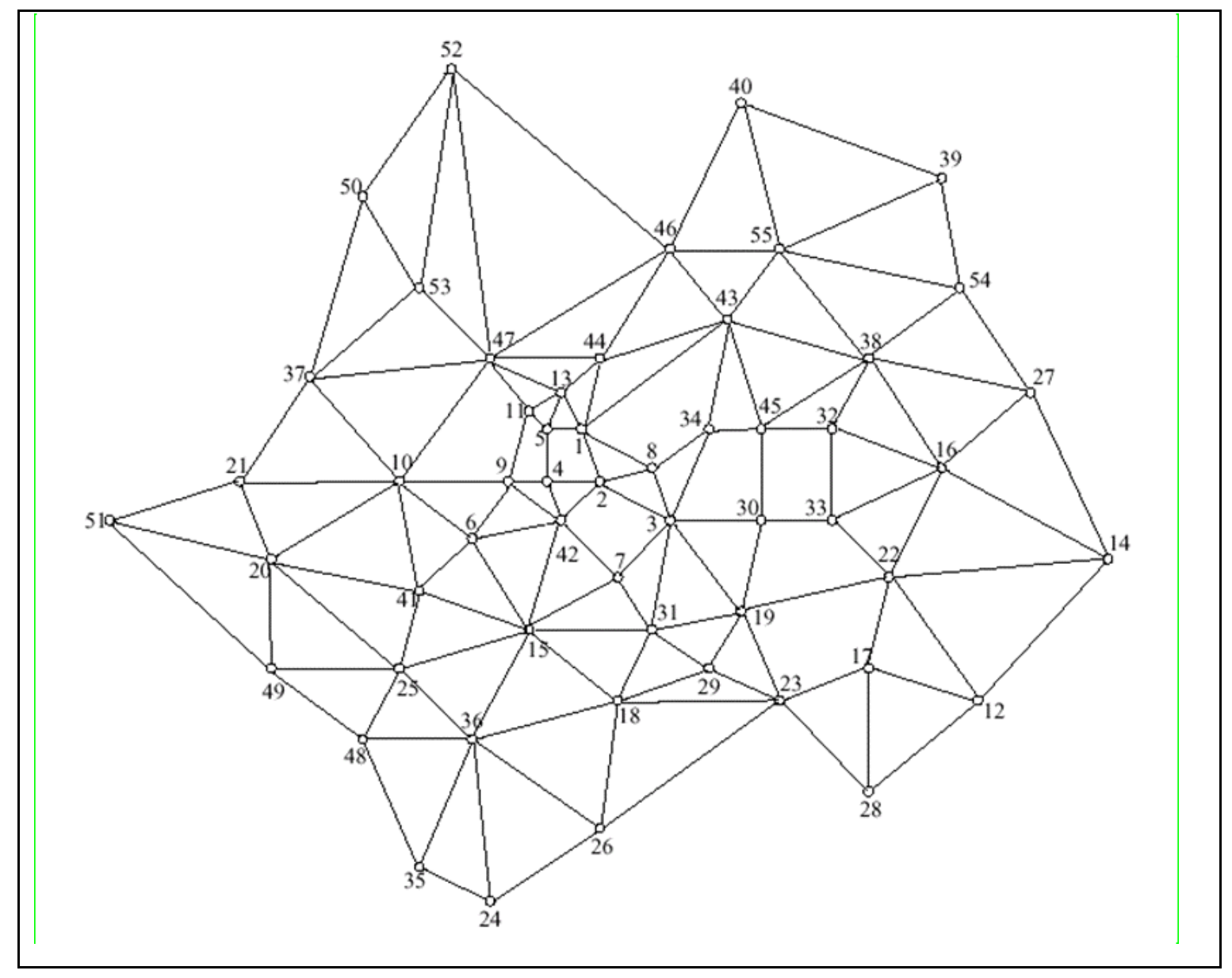

